\title{
PERENCANAAN IPAL BIOFILTER DI UPTD KESEHATAN PUSKESMAS GONDANGWETAN KABUPATEN PASURUAN
}

\author{
Siti Komariyah ${ }^{\star \star}$ ) dan Sugito*)
}

\begin{abstract}
Abstrak
Karakteristik air limbah puskesmas dengan rawat inap hampir secara keseluruhan memiliki kesamaan dengan air limbah rumah sakit. Air limbah puskesmas dapat mencemari lingkungan baik secara fisik, kimia, dan biologis.Oleh karena itu perlu dikembangkan teknologi pengolahan air limbah yang sederhana, biaya murah, mudah operasinya serta mempunyai efisiensi pengolahan polutan yang tinggi. Salah satu alternatif pengolahan air limbah dengan menggunakan biofilter, yaitu suatu reaktor yang dikembangkan dengan prinsip mikroba tumbuh dan melekat pada suatu media filter dan membentuk lapisan biofilm. Tujuan dalam perencanaan ini adalah mendesain IPAL Biofilter UPTD Kesehatan Puskesmas Gondangwetan Kabupaten Pasuruan dengan sistem kombinasi biofilter anaerob-aerob. Metode pengumpulan data yang digunakan adalah survei lapangan, dokumentasi, kajian literature dan analisis laboratorium untuk mengetahui karakteristik fisika - kimia air limbah. Hasil perhitungan perencanaan debit air limbah untuk 5 (lima) tahun mendatang adalah 18 m3/hari. Karakteristik BOD air limbah kualitas medium (220 mg/l). Efisiensi penurunan BOD ditetapkan $90 \%$. Dimensi utama bangunan pengolahan limbah adalah ukuran lebar $1,5 \mathrm{~m}$, kedalaman efektif $1,5 \mathrm{~m}$, panjang bak pengumpul (equalisasi) $1 \mathrm{~m}$, bak sedimentasi awal 1,25 $\mathrm{m}$, bak biofilter anaerob 2,8 $\mathrm{m}$, biofilter aerob 1,4 $\mathrm{m}$, bak pengendapan akhir 1,4 $\mathrm{m}$, dan dilengkapi bak klorinasi. Hasil analisis perhitungan rencana anggaran biaya untuk pembangunan IPAL biofilter adalah sebesar Rp.26.000.000,- (Dua puluh enam juta rupiah).
\end{abstract}

Kata Kunci : Air limbah, Biofilter, IPAL, Puskesmas

\section{PENDAHULUAN}

Pencemaran air permukaan dan air tanah berpotensi menjadi penyebab timbulnya berbagai macam penyakit saluran pencernaan. Hal ini terjadi akibat air limbah yang mengandung bahan pencemar tidak ditangani secara semestinya. Air limbah dari suatu sumber pencemar dapat dibuang ke lingkungan setelah melalui proses pengolahan standar. Pengolahan air limbah harus dapat mereduksi kandungan bahan pencemar sampai tingkatan tertentu yang sesuai dengan baku mutu air limbah.

Unit Pelaksana Teknis Dinas (UPTD) Kesehatan Puskesmas Gondang wetan Kabupaten Pasuruan memberikan pelayanan kesehatan dasar strata pertama kepada masyarakat. Pelayanan tersebut meliputi kegiatan :

pelayanan rawat jalan, rawat inap, persalinan, analisis laboratorium dan kamar obat. Hasil observasi pendahuluan menunjukan bahwa puskesmas ini termasuk salah satu puskesmas dengan rawat inap di wilayah Kabupaten Pasuruan, namun belum memiliki instalasi pengolahan air limbah (IPAL) yang standar.

Karakteristik air limbah puskesmas dengan rawat inap hampir secara keseluruhan memiliki kesamaaan dengan air limbah rumah sakit. Sumber air limbah puskesmas termasuk kategori limbah domestik berasal dari : buangan kamar mandi, dapur, air bekas cucian pakaian, limbah cair klinis berupa air bekas cuci luka, cucian darah, dan air limbah laboratorium. Berdasarkan karakteristik fisis, kimia, dan biologis air limbah puskesmas harus diolah sebelum dibuang ke badan air penerima.

Salah satu teknologi pengolahan air limbah domestik adalah Biofilter. Teknologi Biofilter saat ini banyak dikembangkan karena memiliki beberapa keunggulan antara lain pengoperasiannya mudah, lumpur yang dihasilkan sedikit, tahan terhadap fluktuasi debit aliran maupun fluktuasi beban/konsentrasi, tingkat efisiensinya tinggi serta dapat menghilangkan padatan tersuspensi dengan baik (BPPT, 2006). 
**) Pegawai Dinkes Kabupaten Pasuruan

*) Dosen Teknik Lingkungan

Universitas PGRI Adi Buana Surabaya

Tujuan dari penelitian ini adalah menentukan kapasitas IPAL UPTD Kesehatan Puskesmas Gondangwetan Kabupaten Pasuruan untuk operasional 5 (lima) tahun mendatang. Perencanaan ini meliputi dimensi utama bangunan IPAL Biofilter dan perhitungan anggaran biaya pembangunannya. Parameter utama kualitas air limbah yang digunakan untuk perencanaan IPAL Biofilter adalah Biological Oxygen Demand (BOD) dengan kualitas medium. Manfaat hasil penelitian ini adalah untuk memberikan sumbangan informasi/masukan bagi UPTD Kesehatan Puskesmas Gondangwetan dan Dinas Kesehatan Kabupaten Pasuruan dalam pengolahan air limbah khususnya puskesmas. Hasil pengolahan air limbah adalah efluen berupa air terolah yang sudah memenuhi baku mutu limbah cair domestik

\section{KAJIAN PUSTAKA}

\section{Air limbah Rumah Sakit}

Air limbah rumah sakit adalah limbah kompleks dan mempunyai potensi bahaya serius baik jangka pendek maupun jangka panjang. Menurut Keputusan Gubernur Jawa Timur Nomor 61 tahun 1999 bahwa limbah cair adalah limbah dalam wujud cair yang dihasilkan oleh semua kegiatan rumah sakit yang dibuang ke lingkungan, dan diduga dapat menurunkan kualitas lingkungan. Air limbah rumah sakit adalah seluruh buangan cair yang berasal dari hasil proses seluruh kegiatan rumah sakit. Sumber-sumber tersebut meliputi : buangan kamar mandi, dapur, air bekas cucian pakaian; air limbah klinis yakni air limbah yang berasal dari kegiatan klinis rumah sakit misalnya air bekas cucian luka, cucian darah, cucian peralatan bekas pakai, air limbah laboratorium, dan kamar bersalin (Said, 2006).

Proses pengolahan air limbah umumnya dibagi menjadi empat tahapan yaitu :
1. Pengolahan pendahuluan (Pre treatment)
2. Pengolahan tahap pertama (Primary treatment)
3. Pengolahan tahap kedua (Secondary treatment)
4. Pengolahan tahap ketiga atau pengolahan lanjutan (Tertiary treatment)

\section{Pengolahan Air Limbah dengan Proses Biofilm (Film Mikrobiologis) \\ Menurut Metcalf \& Eddy (2004)}

bahwa Biofilter adalah suatu istilah dari reaktor yang dikembangkan dengan prinsip mikroba tumbuh dan berkembang pada suatu media filter dan membentuk lapisan biofilm (attached growth). Biofilter merupakan salah satu pengolahan limbah cair secara biologis, proses kerjanya memanfaatkan kehidupan mikroorganisme untuk menguraikan polutan.

Di dalam proses pengolahan air limbah dengan proses biakan melekat (attached growth), prinsip dasarnya adalah mengalirkan air limbah ke dalam suatu biakan mikroorganisme yang melekat di permukaan unggun media. Polutan yang ada di dalam air limbah akan diuraikan oleh mikroorganisme tersebut menjadi senyawa yang tidak mencemari lingkungan. Proses penguraiannya dapat berlangsung secara aerob dan anaerob, atau kombinasi anaerob dan aerob.

Media biofilter yang digunakan secara umum dapat berupa material organik atau bahan material anorganik. Media biofilter dari bahan organik misalnya plastik dalam bentuk tali, bentuk jaring, bentuk butiran tak teratur (random packing), bentuk papan (plate), bentuk sarang tawon dan lainlain. Media dari bahan anorganik misalnya batu pecah (split), kerikil,batu kali, batu marmer, zeolit, batu tembikar, batu bara (kokas/anthrasit) dan lainnya. Penggunaan batu apung untuk media biofilter mampu menurunkan BOD air limbah kantin sampai removal 90\% (Rosalia, 2006). Penggunaan media koral dapat menurunkan BOD air limbah domestik sampai 92\% (Sugito,2008)

\section{Prinsip Kerja IPAL Biofilter}

Prinsip kerja dari IPAL Biofilter adalah sebagai berikut :

1. Air limbah dialirkan masuk ke bak pengendap awal, untuk mengendapkan partikel lumpur, pasir, dan kotoran organik tersuspensi. Bak pengendapan juga berfungsi sebagai bak pengurai senyawa organik yang berbentuk padatan, pengurai lumpur (sludge digestion) dan penampung lumpur.

2. Air limpasan dari bak pengendap awal selanjutnya dialirkan ke bak kontaktor anaerob (biofilter anaerob) dengan arah aliran dari atas ke bawah. Bak 
kontaktor anaerob tersebut dapat diisi dengan media filtrasi seperti kerikil, batu kali, marmer, pecahan genteng atau media dari PVC. Setelah beberapa hari operasi, pada permukaan media filter akan tumbuh lapisan film mikroorganisme. Mikroorganisme inilah yang akan menguraikan zat organik yang belum terurai pada bak pengendap.

3. Air limbah dari bak kontaktor (biofilter) anaerob dialirkan ke bak kontaktor aerob. Media biofilter aerob diisi dengan media seperti pada bak anaerob. Aerasi diberikan dengan menggunakan blower untuk kehidupam mikroorganisme. Pada tahap ini akan terjadi proses nitrifikasi, sehingga efisiensi penghilangan ammonia menjadi lebih besar. Proses ini sering dinamakan aerasi kontak (Contact Aeration).

Air limpasan dari bak aerasi, dialirkan ke bak pengendap akhir. Fungsi bak pengendap akhir adalah untuk mengendapkan lumpur. Sebagian lumpur yang mengandung massa mikroorganisme diresirkulasi kembali ke bagian inlet bak pengendap awal dengan pompa sirkulasi lumpur. Sedangkan air limpasan (over flow) dialirkan ke bak khlorinasi sebelum dibuang ke badan air penerima/sungai atau saluran umum

\section{Keunggulan Proses Pengolahan Biofilter Anaerob-aerob} Menurut Said (2006) beberapa keunggulan proses pengolahan air limbah dengan proses biofilter anaerob-aerob antara lain :

1. Pengoperasiannya mudah

2. Biaya operasi rendah

3. Lumpur yang dihasilkan sedikit

4. Dapat menghilangkan nitrogen dan pospor yang menyebabkan eutropikasi

5. Suplai udara untuk aerasi relatif keci

6. Dapat digunakan untuk air limbah dengan beban BOD yang cukup tinggi

7. Pengaruh penurunan suhu terhadap efisiensi pengolahan kecil

8. Dapat menghilangkan padatan tersuspensi (SS) dengan baik

Hasil analisis kualitas air limbah

sebelum dan sesudah pengolahan di Rumah Sakit "Makna" Ciledug-Tangerang, dengan proses "Kombinasi Biofilter AnaerobAerob" dapat menurunkan kandungan zat organik (BOD) dari $419 \mathrm{mg} / \mathrm{l}$ turun menjadi
16,6 mg/l (efisiensi penurunan BOD 96\%), konsentrasi COD dari $729 \mathrm{mg} / \mathrm{l}$ turun menjadi $52 \mathrm{mg} / \mathrm{l}$ (efisiensi penurunan COD 92,8\%), dan padatan tersuspensi dari $825 \mathrm{mg} / \mathrm{l}$ menjadi $10 \mathrm{mg} / \mathrm{l}$ (efisiensi penurunan SS 98,7\%). Hasil pengolahan berupa air olahan yang sangat jernih. Konsentrasi detergen (MBAS) di dalam air limbah dapat diturunkan dari $12 \mathrm{mg} / \mathrm{l}$ menjadi $2,5 \mathrm{mg} / \mathrm{l}$ (efisiensi penurunan detergen $79 \%$ ). Untuk proses pengolahan air limbah dengan kapasitas 10-15 m3 per hari hanya membutuhkan listrik 65 watt, yakni untuk blower udara 40 watt dan pompa sirkulasi 25 watt, sehingga biaya operasi sangat efisien (Said, 2006).

Faktor-faktor yang mempengaruhi kinerja biofilter antara lain:

1. Temperatur

2. Oksigen terlarut

3. Derajat keasaman larutan $(\mathrm{pH})$

4. Nutrien

5. Beban hidrolik

6. Beban organik (Slamet \& Masduqi, 2000).

\section{METODE PENELITIAN}

IPAL Biofilter dalam perencanaan ini adalah sistem biofilter kombinasi antara biofilter anaerob dan biofilter aerob.

\section{Lokasi penelitian}

Lokasi perencanaan IPAL Biofilter adalah di UPTD Kesehatan Puskesmas Gondang wetan yang terletak di Jl. Raya Gondangwetan No. 14 Kecamatan Gondangwetan Kabupaten Pasuruan.

\section{Metode Pengumpulan Data}

Metode pengumpulan data yang digunakan dalam penelitian ini adalah :

1. Survey untuk mengetahui keadaan di lapangan mengenai kondisi jaringan air limbah, pengolahan limbah sebelumnya dan ketersediaan lahan yang ada

2. Analisis Laboratorium untuk mengetahui karakteristik atau kualitas air limbah awal yang akan digunakan sebagai dasar dalam perencanaan IPAL.

3. Metode dokumentasi untuk memperoleh data sekunder tentang profil UPTD Kesehatan Puskesmas Gondangwetan Kabupaten Pasuruan dan rencana pengembangan 
puskesmas untuk 5 (lima) tahun ke depan

4. Kajian literatur yang relevan untuk dasar perhitungan debit dan kriteria teknik dimensi utama bangunan pengolahan air limbah dari referensi yang mendukung.

\section{HASIL DAN PEMBAHASAN}

Karakteristik Limbah Cair Puskesmas

Hasil analisis laboratorium air limbah UPTD Kesehatan Puskesmas Gondangwetan adalah BOD $=172 \mathrm{mg} / \mathrm{l}$; $\mathrm{COD}=302 \mathrm{mg} / \mathrm{l} ; \mathrm{TSS}=72 \mathrm{mg} / \mathrm{l}$; dan $\mathrm{pH}=$ 6,5 . Berdasarkan hasil pengujian tersebut ternyata air limbah Puskesmas Gondangwetan tidak memenuhi persyaratan baku mutu air limbah rumah sakit yang ditetapkan sesuai Surat Keputusan Gubernur Jawa Timur No. 61 tahun 1999. Hal ini yang mendukung untuk dilakukan pengolahan air limbah yang memadai sebelum dibuang ke sungai/saluran umum

Prediksi parameter BOD setelah peningkatan jumlah kunjungan pasien dan pengembangan pelayanan kesehatan untuk 5 tahun mendatang akan mengalami kenaikan $\mathrm{BOD} \pm 25 \%$, sehingga besarnya $\mathrm{BOD}=172 \mathrm{mg} / \mathrm{l}+(0,25 \times 172) \mathrm{mg} / \mathrm{l}=215$ $\mathrm{mg} / \mathrm{l}$. Berdasarkan kriteria karakteristik air buangan/limbah menurut Metcalf \& Eddy (2004), maka termasuk range BOD $220 \mathrm{mg} / \mathrm{l}$ dengan kategori kualitas medium.

Debit air limbah yang dihasilkan oleh Puskesmas Gondangwetan dalam perencanaan untuk 5 tahun mendatang adalah $18 \mathrm{~m}^{3} / \mathrm{hr} \approx 0,2 \mathrm{l} /$ det.

\section{Skenario penurunan konsentrasi BOD}

Efisiensi penurunan BOD (BOD removal) pada proses pengolahan kombinasi biofilter anaerob-aerob tersebut direncanakan dari $220 \mathrm{mg} / \mathrm{l}$ menjadi $20 \mathrm{mg} / \mathrm{l}$ atau sebesar $90 \%$, sehingga diharapkan air olahan yang dihasilkan sudah memenuhi baku mutu air limbah.

\section{Perhitungan Desain IPAL Biofilter}

1. Bak Equalisasi/Bak Pengumpul Debit $(\mathrm{Q})=18 \mathrm{~m}^{3} / \mathrm{hr}$, debit puncak $\left(Q\right.$ peak) $200 \%=36 \mathrm{~m}^{3} / \mathrm{hr}$ (Noerbambang, 2005), dengan waktu tinggal $=1$ jam, maka diperoleh Volume bak $=36 \mathrm{~m}^{3} / \mathrm{hr} \times 1 / 24 \mathrm{hr}$

$$
=1,5 \mathrm{~m}^{3}
$$

Direncanakan dimensi bak berbentuk persegipanjang dengan ukuran :

ditentukan lebar $=1,5 \mathrm{~m}$, maka panjang $=1 \mathrm{~m}$, kedalaman efektif $=1 \mathrm{~m}$ dan tinggi ruang bebas $=0,25 \mathrm{~m}$, sepeti pada gambar 1 dibawah ini.

Bak Equlisasi dilengkapi dengan bar screen untuk menyaring sampah padat yang kemungkinan masuk ke IPAL.

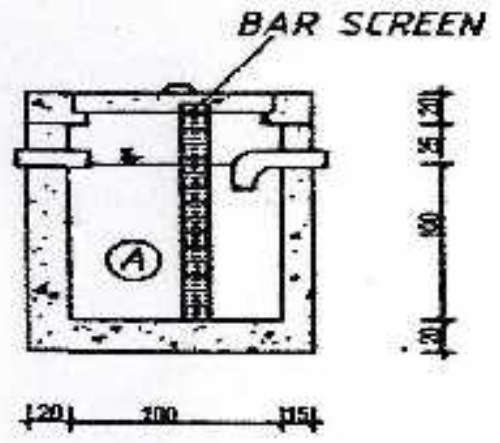

Gambar 1 . Desain Bak

Equalisasi/Pengumpul

2. Bak Sedimentasi Awal

$\begin{array}{ll}\text { Debit }(\mathrm{Q}) & =18 \mathrm{~m}^{3} / \mathrm{hari} \\ \mathrm{BOD} \text { in } & =220 \mathrm{mg} / \mathrm{l} \\ \text { Efisiensi } & =25 \% \\ \text { BOD out } & =165 \mathrm{mg} / \mathrm{l} \\ \text { Waktu tinggal } & =4 \mathrm{jam}, \\ \text { Volume bak } & =18 \mathrm{~m}^{3} / \mathrm{hr} \times 4 / 24 \mathrm{hr} \\ & =3 \mathrm{~m}^{3}\end{array}$

Direncanakan dimensi bak berbentuk persegipanjang dengan ukuran :

lebar $=1,5 \mathrm{~m}$, maka panjang $=1,25 \mathrm{~m}$, kedalaman efektif $=1,5 \mathrm{~m}$, tinggi ruang bebas $=0,25 \mathrm{~m}$, seperti pada gambar 2 dibawah ini

Untuk memperpanjang lintasan aliran air limbah agar tidak terjadi aliran singkat maka dibuat aliran zigzag dengan menambahkan sekat pada permukaan air limbah.

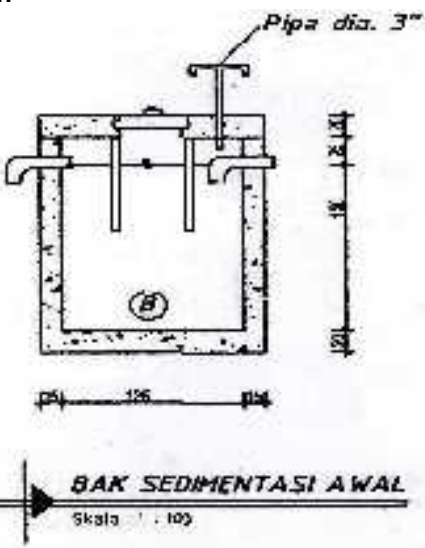


Gambar 2 . Desain Bak Sedimentasi Awal

\section{Bak Biofilter Anaerob}

$\begin{array}{ll}\text { Debit }(\mathrm{Q}) & =18 \mathrm{~m}^{3} / \mathrm{hari} \\ \text { BOD in } & =165 \mathrm{mg} / \mathrm{l} \\ \text { Efisiensi } & =70 \% \\ \text { BOD out } & =49,5 \mathrm{mg} / \mathrm{l} \\ \text { Ditetapkan } & \text { Beban BOD per volume } \\ \text { media } \quad=0,75 \mathrm{~kg} \mathrm{BOD} / \mathrm{m}^{3} / \text { hari } \\ \text { maka : } \\ \text { Beban BOD dalam air limbah }= \\ 18 \mathrm{~m}^{3} / \mathrm{hr} \times 165 \mathrm{~g} / \mathrm{m}^{3}=2.970 \mathrm{~g} / \mathrm{hr}=2,97 \\ \mathrm{~kg} / \mathrm{hr} \\ \text { Volume media yang diperlukan } \\ 2,97 \mathrm{~kg} / \mathrm{hr}=3,96 \mathrm{~m}^{3} \\ 0,75 \mathrm{~kg} / \mathrm{m}^{3} / \mathrm{hr}\end{array}$

Bila volume media yang diperlukan = $60 \% \times$ total volume reaktor maka, volume total reaktor yang diperlukan $=100 / 60 \mathrm{x}$ $3,96 \mathrm{~m}^{3}=6,6 \mathrm{~m}^{3}$.

Waktu tinggal air limbah dalam reaktor $=\frac{6,6 \mathrm{~m}^{3} \times 24 \mathrm{jam} / \mathrm{hr}}{18 \mathrm{~m}^{3} / \mathrm{hr}}=8,8 \mathrm{jam}$

Sehingga diperoleh reaktor biofilter anaerob dengan dimensi :

lebar $=1,5 \mathrm{~m}$, maka panjang $=2,8 \mathrm{~m}$, kedalaman efektif $=1,5 \mathrm{~m}$, tinggi ruang bebas $=0,25 \mathrm{~m}$. jumlah ruang biofilter $=$ dibagi 2 ruangan.

Dimensi media biofilter anaerob direncanakan sebagai berikut :

Tinggi media $\quad=0,9 \mathrm{~m}$

Tinggi ruang lumpur $=0,4 \mathrm{~m}$

Tinggi air di atas media $=0,2 \mathrm{~m}$

Jadi volume total media biofilter anaerob $=0,9 \mathrm{~m} \times 1,5 \mathrm{~m} \times 2,8 \mathrm{~m}=3,78$ $\mathrm{m}^{3}$, seperti pada gambar 3 .

Media dalam perencanaan ini menggunakan material kerikil atau batu pecah (split) dengan ukuran diameter 2-3 $\mathrm{cm}$. Pemilihan media ini dengan alasan memiliki luas permukaan spesifik $100-200$ $\mathrm{m}^{2} / \mathrm{m}^{3}$, harganya murah, mudah diperoleh di wilayah setempat dan telah teruji pada aplikasi pengolahan limbah dengan trickling filter (Metcalf \& Eddy, 2004).

4. Bak Biofilter Aerob

$$
\begin{array}{ll}
\text { Debit (Q) } & =18 \mathrm{~m}^{3} / \mathrm{hari} \\
\text { BOD in } & =49,5 \mathrm{mg} / \mathrm{l} \\
\text { Efisiensi } & =60 \% \\
\text { BOD out } & =20 \mathrm{mg} / \mathrm{l}
\end{array}
$$

Beban BOD dalam air limbah

$=18 \mathrm{~m}^{3} / \mathrm{hr} \times 49,5 \mathrm{~g} / \mathrm{m}^{3}=891 \mathrm{~g} / \mathrm{hr}$

$=0,891 \mathrm{~kg} / \mathrm{hr}$

$$
\text { BOD removal }=60 \% \times 0,891 \mathrm{~kg} / \mathrm{hr}
$$$$
=0,53 \mathrm{~kg} / \mathrm{hr}
$$

Jika ditetapkan Beban BOD per volume media $=0,4 \mathrm{~kg} \mathrm{BOD} / \mathrm{m}^{3} /$ hari, maka volume media yang diperlukan

$$
=\frac{0,53 \mathrm{~kg} / \mathrm{hr}}{0,4 \mathrm{~kg} / \mathrm{m}^{3} / \mathrm{hr}}=1,325 \mathrm{~m}^{3}
$$

Volume media $=40 \% \times$ volume reaktor

Volume reaktor aerob diperlukan

$=100 / 40 \times 1,325 \mathrm{~m}^{3}=3,125 \mathrm{~m}^{3}$

Dalam perencanaan ini reaktor biofilter aerob terdiri dari 2 bagian yaitu bak untuk aerasi dan bak untuk media filter.

Sehingga diperoleh dimensi bak sebagai berikut :

a. Bak aerasi :

Lebar $=1,5 \mathrm{~m}$, kedalaman efektif $=$ $1,5 \mathrm{~m}$, panjang $=0,4 \mathrm{~m}$ dan tinggi ruang bebas $=0,25 \mathrm{~m}$.

b. Bak media biofilter :

Lebar $=1,5 \mathrm{~m}$, kedalaman efektif $=$ $1,5 \mathrm{~m}$, panjang $=1 \mathrm{~m}$ dan tinggi ruang bebas $=0,25 \mathrm{~m}$.

Tinggi media mikroba $\quad=0,9 \mathrm{~m}$ Tinggi ruang lumpur $\quad=0,4 \mathrm{~m}$ Tinggi air di atas media $=0,2 \mathrm{~m}$ Total volume reaktor biofilter aerob $=1,5 \mathrm{~m} \times 1,5 \mathrm{~m} \times 1,4 \mathrm{~m}=3,15 \mathrm{~m}^{3}$ Waktu tinggal air limbah

$=\underline{3,15 \mathrm{~m}^{3}} \times 24 \mathrm{jam} / \mathrm{hr}=4,2 \mathrm{jam}$ $18 \mathrm{~m}^{3} / \mathrm{hr}$

Volume total efektif media biofilter $=1,5 \mathrm{~m} \times 1 \mathrm{~m} \times 0,9 \mathrm{~m}=1,35 \mathrm{~m}^{3}$

Perhitungan kebutuhan oksigen dalam perencanaan biofilter ini adalah sebanding dengan jumlah BOD yang dihilangkan, yaitu : $0,5 \mathrm{~kg} / \mathrm{hr}$.

Faktor keamanan $= \pm 2,0$, maka Kebutuhan oksigen teoritis $=2 \times 0,5$ $\mathrm{kg} / \mathrm{hr}=1 \mathrm{~kg} / \mathrm{hr}$

Berat udara pada suhu $28^{\circ} \mathrm{C}=1,1725$ $\mathrm{kg} / \mathrm{m}^{3}$

Asumsi jumlah oksigen di dalam udara $=23,2 \%$ Jumlah kebutuhan udara teoritis :

udara

$$
\begin{aligned}
& \text { 1 kg/hr } \\
& =\frac{1,1725 \mathrm{~kg} / \mathrm{m}^{3}}{} \mathrm{x} 0,232 \quad \mathrm{gO}_{2} / \mathrm{g} \\
& =3,676 \mathrm{~m}^{3} / \mathrm{hr}
\end{aligned}
$$

Apabila efisiensi diffuser $=5 \%$ maka kebutuhan udara aktual $=\underline{3,676 \mathrm{~m}^{3} / \mathrm{hr}}=73,52 \mathrm{~m}^{3} / \mathrm{hr}=51 \mathrm{l} / \mathrm{mnt}$ 0,05

Blower udara yang dapat digunakan untuk mensuplai udara ke dalam air limbah dengan kapasitas $\pm 75 \mathrm{l} / \mathrm{menit}$ adalah tipe Hi BLOW 100. Diffuser yang digunakan adalah Perforated Pipe Diffusser atau yang setara. 


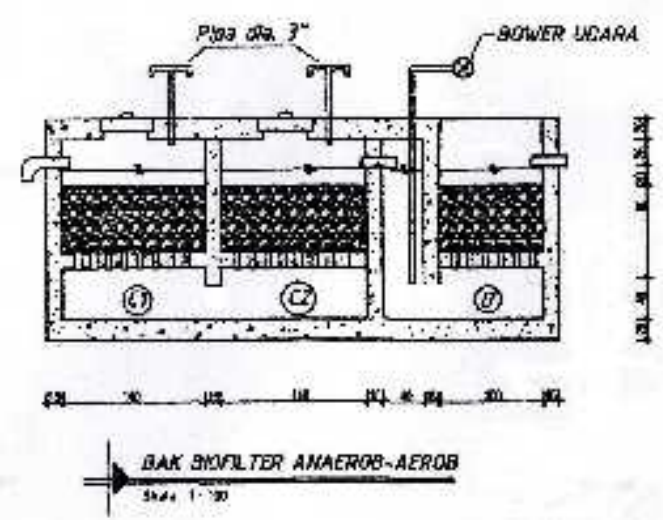

Gambar 3 . Desain Bak Biofilter Anaerob-Aerob

5. Bak Sedimentasi Akhir

$$
\begin{aligned}
& \text { Debit }(\mathrm{Q}) \quad=18 \mathrm{~m}^{3} / \text { hari } \\
& \text { Waktu tinggal }=4 \mathrm{jam} \\
& \text { BOD }=20 \mathrm{mg} / \mathrm{l}
\end{aligned}
$$

Volume bak sedimentasi akhir

$=18 \mathrm{~m}^{3} / \mathrm{hr} \times 4 / 24 \mathrm{hr}=3 \mathrm{~m}^{3}$

Dimensi bak direncanakan berbentuk persegipanjang :

Bila lebar $=1,5 \mathrm{~m}$, maka panjang $=1,4$ $\mathrm{m}$, Kedalaman efektif $=1,5 \mathrm{~m}$, tinggi ruang bebas $=0,25 \mathrm{~m}$.

Volume efektif $=1,4 \mathrm{~m} \times 1,5 \mathrm{~m} \times 1,5 \mathrm{~m}$ $=3,15 \mathrm{~m}^{3}$ (Gambar 4)
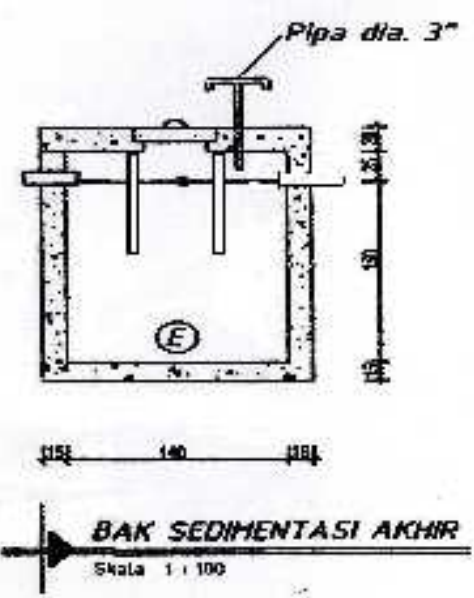

Gambar 4 . Desain Bak Sedimentasi Akhir

6. Bak Desinfeksi

Klorinasi dengan bahan kaporit yang diinjeksikan menggunakan dosing pump/infuse chlorinator.

Perhitungan kebutuhan kaporit/hari

$=0,2 \mathrm{l} / \mathrm{det} \times 100 / 70 \times 3 \mathrm{mg} / \mathrm{l}$

$=0,857 \mathrm{mg} / \mathrm{det}$

$=74,045 \mathrm{mg} / \mathrm{hr}$

$=0,74 \mathrm{~kg} / \mathrm{hr}$
Berdasarkan hasil perhitungan, gambar perencanaan IPAL biofilter untuk pengolahan air limbah UPTD Kesehatan Puskesmas Gondangwetan Kabupaten Pasuruan dapat dilihat pada tabel 1 dan gambar 5.

Berdasarkan hasil perhitungan analisa biaya konstruksi bangunan IPAL Biofilter adalah sebesar Rp.26.000.000,- (Dua puluh enam juta rupiah) termasuk biaya tak terduga $10 \%$. (Zainal, 2005).

\section{Operasional dan pemeliharaan IPAL}

\section{Biofilter}

Hal-hal penting yang harus dilakukan agar IPAL Biofilter dapat mengolah air limbah sesuai efisiensi yang diharapkan adalah sebagai berikut :

1. Pengolahan pendahuluan (Pretreatment) dengan bak penangkap lemak dan netralisasi asam pada air limbah laboratorium dilakukan agar kinerja proses mikroorganisme dalam biofilter lebih optimal.

2. Pada masa pembiakan mikroorganisme (seeding) dibutuhkan nutrien/sumber makanan mikrooganisme dan oksigen terlarut yang cukup 1-2 mg/l, sehingga aklimatisasi stabil.

3. Pemeliharaan IPAL Biofilter meliputi pengurasan lumpur, pencucian ulang media filter (backwashing) dan pencegahan pengelupasan lapisan biofilm (sloughing) dilakukan sesuai kebutuhan.

\section{SIMPULAN}

Dari hasil perencanaan diperoleh kesimpulan sebagai berikut :

1. Debit air limbah UPTD Kesehatan Puskesmas Gondangwetan Kabupaten Pasuruan adalah $18 \mathrm{~m}^{3} /$ hari.

2. Dimensi IPAL Biofilter untuk pengolahan air limbah UPTD Kesehatan Puskesmas Gondangwetan Kabupaten Pasuruan seperti pada tabel 1.

3. Efisiensi penurunan BOD (BOD removal) pada proses biofilter kombinasi anaerobaerob ditetapkan $90 \%$ agar efluen yang dihasilkan memenuhi baku mutu air limbah rumah sakit.

4. Rencana Anggaran Biaya (RAB) Pembangunan IPAL Biofilter UPTD Kesehatan Puskesmas Gondangwetan Kabupaten Pasuruan adalah Rp.26.000.000,- (Duan puluh enam juta rupiah ) termasuk biaya tak terduga sebesar $10 \%$. 
Siti Komariyah dan Sugito : Perencanaan Ipal Biofilter di UPTD Kesehatan Puskesmas Gondangwetan Kabupaten Pasuruan

Tabel 1. Hasil Perhitungan Dimensi IPAL Biofilter dengan debit $36 \mathrm{~m}^{3} / \mathrm{hr}$

\begin{tabular}{|c|c|c|c|c|c|c|}
\hline \multirow{2}{*}{ No. } & \multirow{2}{*}{ Unit } & \multicolumn{3}{|c|}{ Dimensi } & \multirow{2}{*}{$\mathrm{Tb}(\mathrm{m})$} & \multirow{2}{*}{$\mathrm{Td}$ (jam) } \\
\hline & & $P(m)$ & $\mathrm{L}(\mathrm{m})$ & $\mathrm{D}(\mathrm{m})$ & & \\
\hline 1. & Bak Equalisasi/Pengumpul & 1 & 1,5 & 1 & 0,25 & 1 \\
\hline 2. & Bak Sedimentasi Awal & 1,25 & 1 , & 1,5 & 0,2 & 3,9 \\
\hline 3. & Bak Biofilter Anaerob & 2,8 & 1, & 1,5 & 0,2 & 8,8 \\
\hline 4. & Bak Biofilter Aerob & 1,4 & 1,5 & 1,5 & 0,25 & 4,4 \\
\hline 5. & Bak Sedimentasi Akhir & 1,4 & 1,5 & 1,5 & 0,25 & 4,5 \\
\hline 6. & Bak Khlorinasi & 0,6 & 0,6 & 0,6 & 0,25 & 0.25 \\
\hline
\end{tabular}

Keterangan : $\mathrm{P}=$ panjang, $\mathrm{L}=$ Lebar, $\mathrm{D}=$ kedalaman efektif, $\mathrm{Tb}=$ tinggi ruang bebas, $\mathrm{Td}$ $=$ time detention (waktu tinggal)

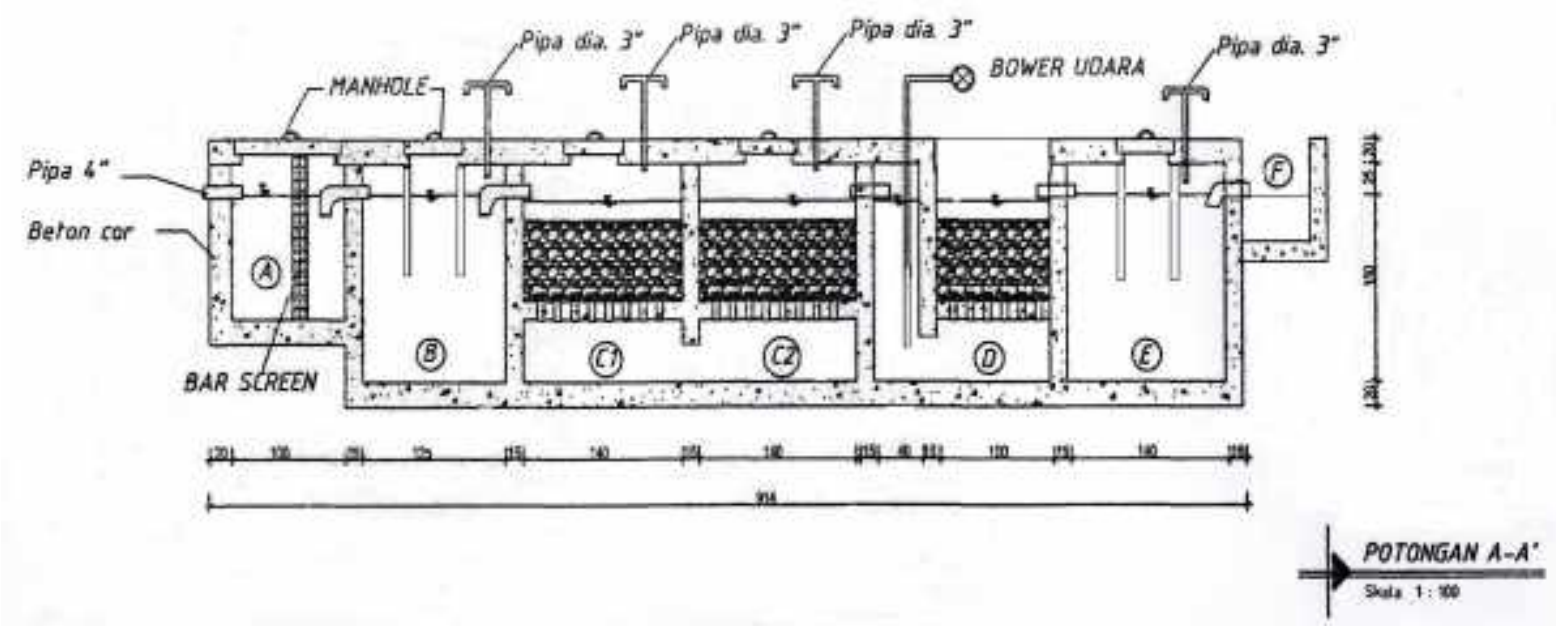

Gambar 5 . Desain IPAL biofilter untuk pengolahan air limbah UPTD Kesehatan Puskesmas Gondangwetan Kab. Pasuruan

\section{DAFTAR PUSTAKA}

BPPT, 2006, Teknologi Pengolahan Limbah Cair Sistem Biakan Melekat (Rumah Sakit, Domestik, Industri), Pusat Teknologi Lingkungan, Jakarta

Keputusan Gubernur Daerah Tingkat I Jawa Timur Nomor : 61 tahun 1999 tertanggal 19 Juli 1999 tentang Baku Mutu Limbah Cair bagi Kegiatan Rumah Sakit di Propinsi daerah Tingkat I jawa Timur.

Metcalf \& Eddy, 2004, Wastewater Engineering Treatment kand Reuse, Fourth Edition, McGrawHill Inc. New York.

Noerbambang, Soufyan M. dan Mirimura, T., 2005. Perancangan dan Pemeliharaan Sistem Plumbing. PT.Pradnya Paramita, Jakarta.

Said, Nusa Idaman, 2006. Instalasi Pengolahan Air Limbah Rumah Sakit. Kelompok Teknologi Pengelolaan Air Bersih dan Air limbah, Pusat Pengkajian dan Penerapan Lingkungan, BPPT, Jakarta.

Slamet, A. dan Masduqi,A, 2000. Satuan Proses. Jurusan Teknik Lingkungan, FTSP-ITS, Surabaya. 
Siti Komariyah dan Sugito : Perencanaan Ipal Biofilter di UPTD Kesehatan Puskesmas Gondangwetan Kabupaten Pasuruan

Sugito, 2008. Pengolahan Air Limbah Domestik di Kota Surabaya dengan Biofilter Aerobik. Jurnal Teknik WAKTU ,ISSN : 1412-1867 Vol 05 N0. 02/ Juli 2007, hal 9-15

Sugito, dan Masrul, 2007. Perencanaan IPAL Biofilter Untuk Pengolahan Limbah Cair Industri Tempe. Jurnal Teknik WAKTU, ISSN : 1412-1867 volume 05 Nomor 02-Juli 2007

Zainal, A.Z, 2005. Analisis Bangunan: Menghitung Anggaran Biaya Bangunan. Gramedia Pustaka Utama, Jakarta. 